\title{
Triploidia Fetal Associada à Diminuição da Subunidade ße do Estriol Não-Conjugado no Soro Materno
}

\author{
Fetal Triploidy Associated With Low Levels of Unconjugated Estriol and \\ Beta-Subunit in Maternal Serum
}

Eduardo Vieira Neto ${ }^{1}$, Luiz Fernando Zingoni ${ }^{2}$, Armando A. Fonseca ${ }^{1}$

\begin{abstract}
RESUMO
Relatamos um caso de triploidia fetal não-molar detectada na $20^{a}$ semana gestacional por cordocentese realizada em razão de estudo ultra-sonográfico que revelou retardo do crescimento intra-uterino e grave oligoidrâmnio. $N a 19^{a}$ semana foram verificados acentuada diminuição da subunidade beta livre da gonadotrofina coriônica humana e do estriol nãoconjugado e niveis de alfa-fetoproteina normais, apontando para um risco aumentado de sindrome de Edwards. Houve morte fetal um dia após a cordocentese e a resolução do caso foi por parto vaginal induzido com misoprostol e ocitocina, sob analgesia peridural. Estudo cromossômico das células sangüineas fetais revelou o cariótipo 69,XXX. O grave retardo do crescimento intra-uterino, a macrocefalia, constatada no estudo anatomopatológico do feto, $e$ os niveis muito baixos de hCG e de estriol não-conjugado sugerem um caso de triploidia por diginia, fertilização de um óvulo diplóide por um espermatozóide haplóide.
\end{abstract}

PALAVRA-CHAVES: Crescimento intra-uterino retardado. Gonadotrofinas. Malformações fetais. Diagnóstico pré-natal.

\section{Introdução}

A triploidia pode ocorrer como resultado da fertilização de um óvulo normal haplóide por 2 espermatozóides normais (dispermia), da fertilização de um óvulo diplóide (erro na meiose materna I ou II) por um espermatozóide haplóide, ou da fertilização de um óvulo haplóide por um espermatozóide diplóide (erro na meiose paterna I ou II). Em $60-70 \%$ dos casos é o resultado da

\footnotetext{
${ }^{1}$ Laboratório DLE \& Centro de Diagnóstico e Pesquisa Dr. Raymundo Britto APAE-Rio, Rio de Janeiro, RJ

${ }^{2}$ Poços de Caldas, MG

Correspondência:

Eduardo Vieira Neto

Av. N. S. de Copacabana, $1018 / 8^{\circ}$ andar

22060-000 - Rio de Janeiro - RJ

Tel.: (021)523-3000; fax: (021)521-9928.

e-mail:dle@dle.com.br
}

presença de um conjunto extra de cromossomos paternos por dispermia 5 .

A triploidia está presente em $1-2 \%$ das gestações em seres humanos. No entanto, é absolutamente excepcional o seu achado em recémnascidos a termo, pois a maioria dos casos termina em aborto espontâneo, geralmente no período embrionário. Com efeito, cerca de 15\% dos produtos de abortamento espontâneo com anomalias cromossômicas são triplóides ${ }^{3,6}$.

Caracteristicamente, estes conceptos triplóides abortados espontaneamente são descritos como molas hidatiformes parciais, sendo resultantes de dispermia ou diandria, conduzindo a niveis elevados de gonadotrofina coriônica humana (hCG) no soro materno ${ }^{10}$.

No entanto, alguns conceptos triplóides sobrevivem até estágios mais avançados da 
gravidez. Estes fetos apresentam um conjunto extra de cromossomos maternos e sofrem grave retardo do crescimento intra-uterino, como resultado de insuficiência placentária. Nestes casos os niveis de hCG e do estriol não-conjugado $\left(\mathrm{uE}_{3}\right)$ no soro materno são muito baixos.

Relatamos um caso de triploidia fetal que cursou com grave retardo do crescimento intrauterino, niveis muito baixos da subunidade beta livre da gonadotrofina coriônica humana (beta-hCG livre) e do $\mathrm{uE}_{3}$ no soro materno e com sobrevivência do concepto até o $2^{\circ}$ trimestre gestacional.

Discutimos a diversidade fenotípica dos fetos triplóides e da função placentária nesta circunstância e sugerimos, a partir dos dados ultrasonográficos, bioquímicos e anatomopatológicos, uma origem para o conjunto extra de cromossomos neste caso.

\section{Relato do Caso}

Paciente RCMK, 29 anos, caucasiana, casada, do lar, gesta I, para 0. Procurou um dos autores (LFZ) em 15/03/1996, em consultório particular em Poços de Caldas, MG; referia DUM em 22/01/1996, estando portanto com 7 semanas e 4 dias de amenorréia (DPP para 28/10/1996). A gravidez foi confirmada por teste qualitativo positivo de beta-hCG urinário e por ultra-sonografia em 01/04/1996, que evidenciou saco gestacional integro contendo embrião único, vivo, com freqüência cardiaca (FC) de $183 \mathrm{bpm}$ e biometria compativel com idade gestacional de 8 semanas.

A paciente negava história anterior de diabetes mélito ou outras patologias endócrinas, infecciosas ou tumorais.

Os exames laboratoriais de rotina pré-natal assim se apresentaram: grupo sangüíneo $\mathrm{A}$, fator $\mathrm{Rh}(+)$; grupo sangüíneo do cônjuge $\mathrm{O}$, fator $\mathrm{Rh}(+)$; VDRL (-); anticorpos anti-Toxoplasma gondii IgG (-) e IgM (-); glicose $72 \mathrm{mg} / \mathrm{dl}$; hemograma e exame de urina tipo 1 normais.

$\mathrm{Na} 2^{a}$ consulta, em 18/06/1996, foi constatado, ao exame clínico, crescimento uterino não-compatível com a idade gestacional e FC fetal basal de $156 \mathrm{bpm}$, com freqüentes episódios de bradicardia de até $80 \mathrm{bpm}$. A gestante foi encaminhada a estudo ultra-sonográfico em 20/ 06/1996, que revelou idade gestacional compativel com 18 semanas, feto com retardo de crescimento intra-uterino, FC fetal arrítmica, com episódios bradicárdicos, ausência de movimentos ativos fetais e oligoidrâmnio grave. Nova ultra-sonografia foi executada em 25/06/1996, revelando o mesmo quadro da ultra-sonografia anterior.
Em 26/06/96, com 19 semanas e 1 dia de gestação, foi feita coleta de sangue materno para rastreamento pré-natal da sindrome de Down e de defeitos de tubo neural. Foram obtidos os seguintes resultados: alfa-fetoproteina $(\mathrm{AFP})=110,2 \mathrm{UI} / \mathrm{ml}$; estriol não-conjugado $\left(\mathrm{uE}_{3}\right)=2,0 \mathrm{nmol} / 1$ e $\beta$-hCG livre $=0,9 \mathrm{ng} / \mathrm{ml}$. Ajustando estes resultados para o peso materno e comparando-os com as medianas de gestações não afetadas de mesma idade gestacional obtidas pelos autores em estudo prévio $^{11}$, obtivemos os seguintes múltiplos da mediana (MoM): $\mathrm{AFP}=2,03 \mathrm{MoM} ; \mathrm{uE}_{3}=0,28 \mathrm{MoM}$ e $\beta$-hCG livre $=0,10 \mathrm{MoM}$. Estes valores apontaram para niveis muito baixos tanto de $\mathrm{uE}_{3}$ quanto de $\beta$ hCG livre, mas para niveis de AFP na faixa superior da normalidade. A análise feita pelo "software" Alpha (Logical Medical Systems, Londres, Reino Unido), levando em consideração os dados bioquímicos e a idade materna, apontou para um risco de sindrome de Edwards fetal superior a 1 em 300 a termo, já que nesta sindrome caracteristicamente são encontrados niveis baixos dos marcadores bioquímicos de soro materno. Havia, portanto, uma indicação de procedimento diagnóstico invasivo para investigação citogenética.

Nova ultra-sonografia realizada em 03/07/ 1996 revelou acentuação do oligoidrâmnio, agora com a quase ausência de líquido amniótico, e feto com retardo do crescimento.

A gestante foi então encaminhada a outro serviço, onde foram efetuadas ultra-sonografia morfológica de alta resolução e coleta de sangue fetal por cordocentese, para estudo citogenético. O estudo ultra-sonográfico de alta resolução, realizado em 16/07/96, mostrou idade gestacional compativel com 20 semanas, feto portador de agenesia parcial do vérmix cerebelar, dolicocefalia, tórax e abdome estreitos, rins não-visíveis, ausência de imagem vesical e oligoidrâmnio acentuado. Neste mesmo dia foi efetuada coleta de sangue fetal por cordocentese. Houve morte fetal um dia após a cordocentese, em 17/07/96. Em 18/07/96 houve resolução do caso por parto vaginal induzido com misoprostol e ocitocina, sob analgesia peridural.

O estudo citogenético dos linfócitos do sangue fetal obtido por cordocentese mostrou o cariótipo $69, \mathrm{XXX}$, indicativo de feto triplóide. O estudo anatomopatológico do feto mostrou peso fetal de $340 \mathrm{~g}$ com $17,5 \mathrm{~cm}$ de comprimento cabeça-nádega, sindactilia do $3^{\circ}$ e $4^{\circ}$ quirodáctilos, à direita e à esquerda, e macrocefalia. Macroscopicamente não foram identificados os órgãos da genitália interna, porém na microscopia, acolado à bexiga urinária, notou-se uma estrutura que sugeriu útero rudimentar.

Posteriormente a paciente teve nova gravidez 
em 20/04/98, com parto normal a termo de feto feminino normal, pesando $2.925 \mathrm{~g}$.

\section{Discussão}

Bogart et al. ${ }^{1}$ foram os primeiros a relatar um caso de niveis muito baixos de hCG no soro materno associados à triploidia fetal $(69, \mathrm{XXX})$. Fejgin et al. ${ }^{2}$ referiram três casos de triploidia fetal $(69, \mathrm{XXX})$ no $2^{\circ}$ trimestre gestacional, diagnosticados por amniocentese, indicada devido a niveis muito baixos de hCG do soro materno. Todos os três casos também apresentaram niveis baixos de $\mathrm{uE}_{3}$ no soro materno e dois deles apresentaram acentuado retardo do crescimento intra-uterino.

Schmidt et al. ${ }^{9}$ descreveram 6 casos de triploidia fetal $(69, \mathrm{XXX})$, dos quais 5 com retardo do crescimento intra-uterino. Todos os casos apresentaram niveis normais de AFP, mas 5 casos apresentaram niveis muito baixos de $\mathrm{hCG}$, e em três casos os niveis de $\mathrm{uE}_{3}$ se mostraram baixos.

O caso por nós relatado de triploidia fetal $(69, \mathrm{XXX})$ e grave retardo do crescimento intrauterino, acompanhado de niveis muito baixos $(0,10$ MoM) de beta-hCG livre, de niveis baixos de $\mathrm{uE}_{3}$ $(0,28 \mathrm{MoM})$ e de niveis de AFP na faixa superior da normalidade, vem corroborar os achados de Fejgin et al. ${ }^{2}$ e de Schmidt et al. ${ }^{9}$.

McFadden e Kalousek ${ }^{8}$ observaram dois fenótipos distintos entre 19 fetos, natimortos e recém-nascidos vivos com triploidia, que foram correlacionados com a origem parental do conjunto haplóide extra. Fetos do tipo I (2 casos) apresentavam crescimento relativamente normal, microcefalia e placenta grande e cística. Por outro lado, fetos do tipo II (17 casos) apresentavam retardo do crescimento intra-uterino, macrocefalia relativa e placenta pequena e não-cística. Num caso de feto do tipo I, foi demonstrado que o conjunto haplóide extra era de origem paterna, ao passo que num caso de feto do tipo II foi provado que a triploidia se devia a um erro na gametogênese materna (triploidia por diginia). Podemos deduzir que os fetos do tipo I com placenta grande e cística devem induzir niveis elevados de hCG no soro materno, ao passo que fetos do tipo II, com placentas ineficientes, devem induzir niveis baixos de hCG no soro materno.

Estudos em animais demonstraram claramente que a origem parental de parte ou de todo o genoma pode ter um impacto significativo sobre o fenótipo do concepto. Este efeito tem sido atribuído a um fenômeno denominado imprinting genômico ${ }^{4}$. Quando o produto da concepção é de origem exclusivamente paterna, pela substituição do pró-núcleo materno por um pró-núcleo paterno, resulta no desenvolvimento exagerado do trofoblasto (mola completa) e atrofia ou supressão do desenvolvimento embrionário; por outro lado, uma constituição exclusivamente materna, pela substituição do pró-núcleo paterno por um prónúcleo materno, resulta na hipoplasia das estruturas extra-embrionárias e desenvolvimento inicialmente normal do embrião.

Nosso caso, que apresentou acentuado retardo do crescimento intra-uterino, verificado em várias ultra-sonografias, e macrocefalia, constatada no estudo anatomopatológico, se enquadra na descrição de feto tipo II de McFadden e Kalousek ${ }^{8}$, sendo provavelmente um caso de triploidia por diginia. Sugerimos que a causa dos niveis muito baixos de hCG foi a insuficiência placentária, fato que foi corroborado pelos níveis baixos de estriol, um conhecido marcador de bom funcionamento placentário.

A maioria dos conceptos triplóides por diandria ou dispermia são abortados no $1^{\circ}$ trimestre, ao passo que os conceptos triplóides por diginia predominam nos estágios mais tardios da gravidez, apesar de apresentarem placentas ineficientes. A explicação para este fato ainda não está clara, mas McFadden e Kalousek ${ }^{8}$ levantaram a hipótese de uma maior incidência de mosaicismo confinado à placenta no caso de fetos do tipo II, com o citotrofoblasto diplóide produzindo uma compensação funcional. Kalousek et al. ${ }^{7}$ já haviam demonstrado que os conceptos com trissomia do 13 ou do $18 \mathrm{com}$ maior sobrevida intra-uterina mais comumente apresentam mosaicismo confinado à placenta com o citotrofoblasto mosaico contendo uma linhagem celular diplóide normal.

O fato de que, além de fetos triplóides por diginia, fetos com trissomia do 18 também estejam associados a retardo do crescimento intra-uterino e níveis muito baixos de hCG no soro materno pode ser indicativo de que a amniocentese visando a estudo citogenético deva ser recomendada a gestantes com niveis muito baixos $(\leq 0,20$ múltiplos da mediana) de hCG no $2^{\circ}$ trimestre gestacional, desde que haja evidências ultra-sonográficas de retardo do crescimento intra-uterino. Este protocolo detectaria o caso por nós descrito neste artigo e 7 dos 9 casos (88\%) de triploidia fetal relatados por Fejgin et al. ${ }^{2}$ e por Schmidt et al. ${ }^{9}$, pois apenas 2 casos $(22 \%)$ apresentaram-se normais ao ultra-som, apesar de estarem associados a níveis baixos de $\mathrm{hCG}$ e de $\mathrm{uE}_{3}$ no soro materno. 


\section{SUMMARY}

We report a case of nonmolar fetal triploidy detected by fetal blood sampling at 20 weeks of gestation, performed as an investigation of intrauterine growth retardation and severe oligohydramnios found by ultrasound scan. At 19 weeks of gestation very low levels of maternal free serum beta-subunit of human chorionic gonadotropin and unconjugated estriol, and normal levels of alpha-fetoprotein were found, which were interpreted as a high risk of fetal Edwards syndrome. Fetal death supervened the day after fetal blood sampling, and the pregnancy was terminated by vaginal delivery induced by misoprostol and oxytocin, under epidural anesthesia. Chromosome study of the fetal blood cells showed a 69,XXX karyotype. The severe intrauterine growth retardation and macrocephaly noted on pathological review plus the very low levels of $h C G$ and unconjugated estriol suggest a fetal gynoid triploidy case, caused by the fertilization of a diploid egg by a haploid sperm.

KEY WORDS: Intrauterine growth retardation. Human chorionic gonadotropin. Fetal malformations.

\section{Referências}

1. Bogart MH, Golbus MS, Sorg ND, Jones OW. Human chorionic gonadotropin levels in pregnancies with aneuploid fetuses. Prenat Diagn 1989; 9:379-84.

2. Fejgin M, Amiel A, Goldberger S, Barnes I, Zer T, Kohn G. Placental insufficiency as a possible cause of low maternal serum human chorionic gonadotropin and low maternal serum unconjugated estriol levels in triploidy. Am J Obstet Gynecol 1992; 167:766-7.
3. Griffin DK, Millie EA, Redline RW, Hassold TJ, Zaragoza MV. Cytogenetic analysis of spontaneous abortions: comparison of techniques and assessment of the incidence of confined placental mosaicism. Am J Med Genet 1997; 72:297-301.

4. Hall JG. Genomic imprinting: review and relevance to human diseases. Am J Hum Genet 1990; 46:857-73.

5. Jacobs PA, Angell RR, Buchanan IM, Hassold TJ, Matsuyama AM, Manuel B. The origin of human triploids. Ann Hum Genet 1978; 42:4957.

6. Kajii T, Ferrier A, Niikawa N, Takahara H, Ohama $\mathrm{K}$, Avirachan S. Anatomic and chromosomal anomalies in 639 spontaneous abortuses. Hum Genet 1980; 55:87-98.

7. Kalousek DK, Barrett IJ, McGillivray BC. Placental mosaicism and intrauterine survival of trisomies 13 and 18. Am J Hum Genet 1989; 44:338-43.

8. McFadden DE, Kalousek DK. Two different phenotypes of fetuses with chromosomal triploidy: correlation with parental origin of the extra haploid set. Am J Med Genet 1991; 38:535-8.

9. Schmidt D, Shaffer LG, McCaskill C, Rose E, Greenberg F. Very low maternal serum chorionic gonadotropin levels in association with fetal triploidy. Am J Obstet Gynecol 1994; 170:77-80.

10. Szulman AE. Trophoblastic disease: clinical pathology of hydatidiform moles. Obstet Gynecol Clin North Am 1988; 15:443-56.

11. Vieira Neto E, Cardoso CBMA, Carvalho ECD, Fonseca AA. Marcadores bioquímicos utilizados em rastreamento pré-natal de sindrome de Down e defeitos de tubo neural no segundo trimestre de gestação: medianas de um grupo brasileiro de gestantes. J Bras Patol 1996; 32:179-87. 